ENVIRONMENTAL EXPOSURE

\title{
Association between self-reported childhood socioeconomic position and adult lung function: findings from the British Women's Heart and Health Study
}

\author{
D A Lawlor, S Ebrahim, G Davey Smith
}

Thorax 2004;59:199-203. doi: 10.1136/thorax.2003.008482

See end of article for authors' affiliations

Correspondence to:

Correspondence to: of Social Medicine University of Bristol, Bristol BS8 2PR, UK; d.a.lawlor@ bristol.ac.uk

Received 9 April 2003

Accepted

8 November 2003
Background: A study was undertaken to assess the associations between indicators of early life socioeconomic position and lung function in older adulthood.

Methods: The associations of self-reported indicators of childhood socioeconomic position with adult lung function (forced expiratory volume in 1 second $\left(F E V_{1}\right)$, forced vital capacity (FVC), and forced expiratory flow rate during mid expiration $\left(\mathrm{FEF}_{25-75}\right)$, all measured using standard procedures) were assessed in a cross sectional study of 3641 British women aged 60-79 years.

Results: In confounder adjusted analyses, each individual indicator of childhood circumstances was inversely associated with each measure of lung function. In the fully adjusted models (including mutual adjustment for each of the other indicators of childhood socioeconomic circumstances), only childhood occupational social class and access to a car were associated with lung function in adulthood. However, there were strong linear trends of worsening lung function with greater numbers of indicators of childhood poverty (all $p$ values $<0.001$ ).

Conclusions: Childhood poverty is associated with poorer lung function in women aged 60-79 years. Adverse childhood circumstances that affect both lung growth and development and cardiovascular disease in later life may explain some of the well known associations between poor lung function and cardiovascular disease, or lung function may be an important mediating factor in this association.
$P$ oor lung function in adulthood is associated with an increased risk of cardiovascular disease and all cause mortality, even among life long non-smokers, but the explanation for these associations is unclear. ${ }^{1-3}$ It is possible that they reflect early life exposures which influence lung growth and development as well as the risk of adult disease. Normal lung growth and development during the intrauterine period and childhood are important for reaching maximum attainable adult lung function. ${ }^{4-6}$ A number of early life factors including maternal smoking, low birth weight, prematurity, and childhood infections-all of which may reflect poor early life socioeconomic circumstances-are associated with reduced lung function in childhood and early adulthood. ${ }^{7-14}$ However, few studies have investigated the associations of socioeconomic position in early life with lung function in older adulthood, and studies of older adults have assessed forced expiratory volume in 1 second $\left(\mathrm{FEV}_{1}\right)$ only and not other measures of lung function. ${ }^{15}{ }^{16}$ If the association between lung function and increased risk of cardiovascular disease in later life reflects early life factors that are associated with both poor lung development and increased risk of adult cardiovascular disease, one would expect childhood socioeconomic position to be inversely associated with adult lung function. Furthermore, specific associations with different measures of lung function may indicate whether the association is related to early life factors associated with lung growth, airways development, or both.

The aim of this study was to examine the associations of early life indicators of socioeconomic position with lung function in older adulthood.

\section{METHODS}

\section{Participants}

Full details of the selection of participants and measurements have been previously reported. ${ }^{17}$ Women aged $60-79$ years were randomly selected from general practitioner lists in 23 British towns. A total of 4286 women (60\% of those invited) participated and baseline data (self-completed questionnaire, research nurse interview, physical examination, and primary care medical record review) were collected between April 1999 and March 2001. Local ethics committee approvals were obtained.

\section{Measurements \\ Lung function tests}

Lung function tests were carried out with a digital meter Vitalograph with an attached printout of forced vital capacity (FVC), forced expiratory volume in 1 second $\left(\mathrm{FEV}_{1}\right)$, and forced mid expiratory flow rate $\left(\mathrm{FEF}_{25-75}\right)$. The Vitalograph was calibrated each day using a 1 litre syringe and automated so that results were adjusted for ambient temperature. For each assessment a research nurse demonstrated the technique to the participants who were given the opportunity to perform some practice efforts. They were then required to perform a minimum of three reproducible FVC measures (within $5 \%$ of maximum FVC produced). The output that produced the highest sum of FVC and $\mathrm{FEV}_{1}$ was used in the analyses. Women who could not perform three reproducible measures or who were unable to attempt the lung function tests were excluded. All assessments were carried out by one of five research nurses who were trained to carry out the assessment in a similar manor.

\section{Early life socioeconomic position}

In the self-completed questionnaire participants were asked whether the house that they had lived in for the longest period as a child had a bathroom and whether it had a hot water supply. They were also asked if, as a child, they shared a bedroom or had their own bedroom and whether their family had access to a car. Childhood social class was derived 
from the longest held occupation of the participant's father. Social class was categorised into one of six social classes based on the Registrar General's occupational classification (ranging from I (professional) to $\mathrm{V}$ (unskilled manual occupations; these were also grouped into two broad categories of manual and non-manual social classes).

\section{Other measurements}

At the research nurse interview all participants brought their current medications and a detailed drugs history was undertaken. Participants were coded as taking respiratory medications if they were currently using any bronchodilator or steroid medications (drugs in sections 3.1-3.3 of the British National Formulary: http://www.bnf.org/). Details of physical activity (type and amount), smoking history (past and current including amount and details of starting and quitting), marital status, and smoking history (past and current including amount and details of starting and quitting) of husbands/long term partners were obtained by self-report from either the research nurse interview or the self-completed questionnaire. Details of the participant's and her husband's occupations were requested in the selfcompleted questionnaire. Adult social class was defined on the basis of the longest held occupation of her husband for married women and her own longest held occupation for single women, and was classified according to the Registrar General's classification in a similar way to childhood social class. Standing height was measured without shoes using a Harpenden stadiometer recording to the nearest millimetre.

\section{Statistical analysis}

Analysis of variance was used to assess between nurse variation in lung function measurements.

A series of linear regression models was used to estimate the association between each indicator of childhood socioeconomic position and each measurement of lung function. In the basic model (model 1) adjustment was made for examining nurse, age, and height squared. The square of the height was used because, in an earlier study of the association between stature and lung function, it was concluded that a proportional model best described the association, ${ }^{18}$ and in our data we found that this was also the case (in a regression model with height this explained $12 \%$ of the variation in $\mathrm{FEV}_{1}$ whereas height squared explained $17 \%)$. Adjustment was then made for potential confounding factors (adult social class, smoking, body mass index, physical activity, and respiratory medication; model 2). In the final model (model 3) additional mutual adjustment for other indicators of early life exposures was undertaken so that the independent effects of each measure could be determined. Because of the strong association between smoking and lung function, simple adjustment for smoking in regression models may be insufficient to account for its potential confounding effects. As a result, the regression models were repeated stratified by smoking status.

In all analyses robust confidence intervals were estimated which take into account the clustering between participants from the same towns.

\section{RESULTS}

Of the 4286 participants, 3911 (91\%) completed adequate lung function measures. Those who were unable to complete adequate measures were older (mean (SD) age 69.8 (5.7) years $v 68.8(5.5)$ years, $p=0.001)$ and were more likely to have ever been smokers (61.7\% (95\% CI 56.6 to 66.6$)$ $v 53.5 \%(95 \%$ CI 52.0 to 55.1), $\mathrm{p}=0.003)$. In total, 3642 women $(85 \%)$ had complete data on lung function measures, all childhood indicators of socioeconomic position, and all confounding variables. Women with complete data were slightly younger than those without complete data (see above). Women who provided self-reported data on childhood socioeconomic position had similar lung function tests to those who did not (all $\mathrm{p}$ values $>0.5$ ). The analyses presented here are for the 3642 women with complete data on all variables included in any analyses. There was evidence of some difference between the nurses in lung function assessments: mean (SD) $\mathrm{FEV}_{1}$ was $2.00(0.53) 1$ for nurse 1, $1.92(0.46) \mathrm{l}$ for nurse 2, $2.02(0.52) \mathrm{l}$ for nurse 3, 2.01 (0.50) l for nurse 4, and $1.96(0.50) \mathrm{l}$ for nurse $5, \mathrm{p}=0.05$ (analysis of variance for difference in means). All lung function measures have therefore been adjusted for examining nurse by including examining nurse as an indicator variable in all analyses.

For women included in the analysis the mean (SD) $\mathrm{FEV}_{1}$ was 1.98 (0.52) l, mean FVC was $2.80(0.75) \mathrm{l}$, and mean $\mathrm{FEF}_{25-75}$ was $1.44(0.70) \mathrm{l}$. The measures of childhood socioeconomic position were all strongly associated with each other (table 1). In particular, those who reported living in a house with no bathroom as a child were also likely to report living in a house with no hot water.

Tables $2-4$ show the associations between each childhood indicator of socioeconomic position and each measure of lung function. In the basic model with adjustment for examining nurse, age and height squared (model 1), all five measures of childhood socioeconomic position were associated with all three measures of lung function, with those from poorer childhood circumstances having worse adult lung function. With adjustment for potential confounding factors (model 2 ), these associations attenuated, although most indicators of childhood socioeconomic position remained associated with $\mathrm{FEV}_{1}$ (table 2) and FVC (table 3), and belonging to a manual social class in childhood remained associated with $\mathrm{FEF}_{25-75}$ (table 4).With further mutual adjustment for each of the other childhood indicators of socioeconomic position (model 3 ), only childhood social class and access to a family car remained associated with $\mathrm{FEV}_{1}$ and FVC and only childhood social class remained associated with $\mathrm{FEF}_{25-75}$. Since living in a house as a child with no bathroom and living in one with no hot water were very strongly associated, the final regression models including all indicators of childhood socioeconomic position were repeated excluding the variable "childhood house without hot water" in order to determine whether colinearity affected the results. None of the point estimates presented in the final columns of tables 2-4 were altered; the confidence intervals for the associations with "childhood house with no bathroom" were all slightly narrower, but none of the other confidence intervals were affected.

Table 5 shows the cumulative effect of poor socioeconomic circumstances on $\mathrm{FEV}_{1}$. There was a strong linear trend of increasingly poorer $\mathrm{FEV}_{1}$ with greater numbers of each indicator of childhood socioeconomic deprivation which remained even with adjustment for potential confounding factors. A woman who had belonged to a manual social class in childhood, lived in a house with no bathroom and no hot water supply, had no family access to a car, and shared a bedroom as a child had an $\mathrm{FEV}_{1}$ that was on average 0.25 standard deviations $(0.52 \mathrm{l})$ lower than one from nonmanual social classes who lived in a house with a bathroom and hot water, had access to a car and her own bedroom. Similar linear trends were seen with FVC and $\mathrm{FEF}_{25-75}$ as the outcomes (all $\mathrm{p}<0.001$ ). Figure 1 shows the different distributions of $\mathrm{FEV}_{1}$ for women who were in the most affluent position in childhood (no adverse socioeconomic indicators), those with three adverse indicators, and those from the most disadvantageous childhood circumstances (all five adverse indicators). The whole distribution is shifted 
Table 1 Associations (crude odds ratios and 95\% confidence intervals) between measures of early life childhood socioeconomic position

\begin{tabular}{|c|c|c|c|c|c|}
\hline & $\begin{array}{l}\text { Manual } \\
\text { childhood } \\
\text { social class }\end{array}$ & $\begin{array}{l}\text { No bathroom in } \\
\text { childhood house }\end{array}$ & $\begin{array}{l}\text { No hot water in } \\
\text { childhood house }\end{array}$ & $\begin{array}{l}\text { No access to a } \\
\text { car as a child }\end{array}$ & $\begin{array}{l}\text { Shared } \\
\text { bedroom } \\
\text { as a child }\end{array}$ \\
\hline $\begin{array}{l}\text { Manual childhood } \\
\text { social class }\end{array}$ & - & & & & \\
\hline $\begin{array}{l}\text { No bathroom in } \\
\text { childhood house }\end{array}$ & 3.5 (2.9 to 4.3$)$ & - & & & \\
\hline $\begin{array}{l}\text { No hot water in } \\
\text { childhood house }\end{array}$ & 3.4 (2.8 to 4.2$)$ & $100.3(80.0$ to 126.8 ) & - & & \\
\hline No access to a & 4.7 (4.0 to 5.7$)$ & 7.8 (5.9 to 10.0$)$ & 13.0 (9.3 to 18.3 ) & - & \\
\hline $\begin{array}{l}\text { car as a child } \\
\text { Shared bedroom } \\
\text { as a child }\end{array}$ & 2.9 (2.5 to 3.4$)$ & 3.5 (3.0 to 4.0$)$ & 3.9 (3.4 to 4.4$)$ & 5.7 (4.7 to 6.9$)$ & - \\
\hline
\end{tabular}

to the left with worsening childhood socioeconomic circumstances.

When the analyses were repeated in strata according to smoking status, the results were similar in women who were life long non-smokers and either single or married to nonsmokers, in women who were life long non-smokers and married to smokers (passive smokers), and women who were current or ex-smokers. There was no strong statistical evidence of any interactions between smoking status and childhood socioeconomic status in their associations with lung function measures (all $\mathrm{p}>0.3$ ).

\section{DISCUSSION}

\section{Main results}

Indicators of childhood poverty were associated with poor lung function in late adulthood even with adjustment for adult socioeconomic position, smoking, and other potential confounding factors. The presence of a bathroom and hot water in the household and sharing a bedroom were not independently associated with poorer adult lung function in models which mutually adjusted for all indicators of childhood poverty, although there was a strong linear trend of poorer lung function with greater number of indicators of childhood poverty. The associations are not caused by childhood poverty being associated with an increased likelihood of smoking, since they were present in women with little or no exposure to smoking throughout their lives, in women exposed only to passive smoke, and in women who are or have been smokers.

\section{Study limitations}

Our response rate $(60 \%)$ is moderate but consistent with other contemporary large epidemiological surveys. ${ }^{19}$ As reported previously, respondents were slightly younger than non-respondents and less likely to have a primary care medical record of stroke or diabetes, although the prevalence of coronary heart disease and cancer did not vary between responders and non-responders. ${ }^{17}$ The associations presented here would only be exaggerated if they were in the opposite direction or markedly weaker among non-responders, which seems unlikely. Our study is cross sectional. Since the temporal nature of the association between childhood circumstances and adult lung function is clear, reverse causality cannot explain our findings. However, women who die prematurely are more likely to be from poorer childhood backgrounds and so survivor bias may have resulted in underestimations of the true associations. We have relied upon self-reporting of childhood circumstances. It is difficult to see how objective measures such as lung function could influence recall, so misclassification is likely to be non-differential and may, as a result, have diluted the associations. We do not have data on important childhood exposures such as maternal smoking and infant and childhood diet which may mediate the associations presented here.

\section{Implications}

We have assessed the associations of early life exposures with three different measures of lung function in an attempt to determine whether early life exposures are associated with

\begin{tabular}{|c|c|c|c|}
\hline \multirow{2}{*}{$\begin{array}{l}\text { Childhood measure } \\
\text { of SEP }\end{array}$} & \multicolumn{3}{|c|}{ Difference $(95 \% \mathrm{Cl})$ in $\mathrm{FEV}_{1}$ (SD) } \\
\hline & Model 1* & Model 2† & Model 3‡ \\
\hline $\begin{array}{l}\text { Manual - non-manual } \\
\text { social class }\end{array}$ & $-0.23(-0.30$ to -0.47$)$ & $-0.16(-0.23$ to -0.10$)$ & \\
\hline $\begin{array}{l}\text { House without bath - } \\
\text { house with bath }\end{array}$ & $-0.13(-0.19$ to -0.07$)$ & $-0.08(-0.13$ to -0.02$)$ & $-0.01(-0.10$ to 0.09$)$ \\
\hline $\begin{array}{l}\text { House without hot water } \\
\text { - house with hot water }\end{array}$ & $-0.13(-0.19$ to -0.08$)$ & $-0.08(-0.14$ to -0.03$)$ & $-0.03(-0.13$ to 0.06$)$ \\
\hline $\begin{array}{l}\text { No car access - car } \\
\text { access }\end{array}$ & $-0.19(-0.27$ to -0.12$)$ & $-0.14(-0.21$ to -0.07$)$ & $-0.10(-0.16$ to -0.02$)$ \\
\hline $\begin{array}{l}\text { Shared bedroom - } \\
\text { bedroom of own }\end{array}$ & $-0.11(-0.17$ to -0.05$)$ & $-0.08(-0.13$ to -0.02$)$ & $-0.03(-0.09$ to 0.03$)$ \\
\hline \multicolumn{4}{|c|}{$\begin{array}{l}\mathrm{SD}=\text { standard deviation ( } 1 \text { standard deviation } \mathrm{FEV}_{1}=0.52 \mathrm{l} \text { ). } \\
\text { *Adjusted for nurse, age, and height squared. } \\
\text { †Adjusted for nurse, age, height squared, smoking, body mass index, physical activity, adult social class, and } \\
\text { respiratory treatment. } \\
\text { †Adjusted for nurse, age, height squared, smoking, body mass index, physical activity, adult social class, } \\
\text { respiratory treatment, and each of the other childhood indicators of SEP (first column). }\end{array}$} \\
\hline
\end{tabular}


Table 3 Multivariable associations of childhood socioeconomic position (SEP) with forced vital capacity (FVC)

\begin{tabular}{|c|c|c|c|}
\hline \multirow{2}{*}{$\begin{array}{l}\text { Childhood measure } \\
\text { of SEP }\end{array}$} & \multicolumn{3}{|c|}{ Difference $(95 \% \mathrm{Cl})$ in FVC (SD) } \\
\hline & Model 1* & Model $2 \dagger$ & Model $3 \ddagger$ \\
\hline $\begin{array}{l}\text { Manual - non-manual } \\
\text { social class }\end{array}$ & $-0.19(-0.26$ to -0.12$)$ & $-0.11(-0.19$ to -0.04$)$ & $-0.09(-0.15$ to -0.01$)$ \\
\hline $\begin{array}{l}\text { House without bath - } \\
\text { house with bath }\end{array}$ & $-0.12(-0.18$ to -0.06$)$ & $-0.06(-0.12$ to 0.00$)$ & $-0.02(-0.08$ to 0.12$)$ \\
\hline $\begin{array}{l}\text { House without hot water } \\
\text { - house with hot water }\end{array}$ & $-0.14(-0.20$ to -0.07$)$ & $-0.08(-0.14$ to -0.02$)$ & $-0.06(-0.16$ to 0.04$)$ \\
\hline $\begin{array}{l}\text { No car access - car } \\
\text { access }\end{array}$ & $-0.20(-0.28$ to -0.13$)$ & $-0.15(-0.23$ to -0.07$)$ & $-0.12(-0.20$ to -0.03$)$ \\
\hline $\begin{array}{l}\text { Shared bedroom - } \\
\text { bedroom of own }\end{array}$ & $-0.09(-0.15$ to -0.03$)$ & $-0.05(-0.11$ to 0.01$)$ & $0.00(-0.07$ to 0.06$)$ \\
\hline
\end{tabular}

$\mathrm{SD}=$ standard deviation ( 1 standard deviation $\mathrm{FVC}=0.75$ I)

*Adjusted for nurse, age, and height squared.

†Adjusted for nurse, age, height squared, smoking, body mass index, physical activity, adult social class, and respiratory treatment.

$\ddagger$ Adjusted for nurse, age, height squared, smoking, body mass index, physical activity, adult social class, respiratory treatment, and each of the other childhood indicators of SEP (first column).

Table 4 Multivariable associations of childhood socioeconomic position (SEP) with forced expiratory flow in mid expiration $\left(\mathrm{FEF}_{25-75}\right)$

\begin{tabular}{|c|c|c|c|}
\hline \multirow{2}{*}{$\begin{array}{l}\text { Childhood measure } \\
\text { of SEP }\end{array}$} & \multicolumn{3}{|c|}{ Difference $(95 \% \mathrm{Cl})$ in $\mathrm{FEF}_{25-75}(\mathrm{SD})$} \\
\hline & Model 1* & Model $2 \dagger$ & Model 3‡ \\
\hline $\begin{array}{l}\text { Manual - non-manual } \\
\text { social class }\end{array}$ & $-0.18(-0.25$ to -0.10$)$ & $-0.14(-0.21$ to -0.07$)$ & $-0.13(-0.21$ to -0.05$)$ \\
\hline $\begin{array}{l}\text { House without bath - } \\
\text { house with bath }\end{array}$ & $-0.08(-0.14$ to -0.01$)$ & $-0.05(-0.12$ to 0.01$)$ & $0.00(-0.10$ to 0.10$)$ \\
\hline $\begin{array}{l}\text { House without hot water } \\
\text { - house with hot water }\end{array}$ & $-0.08(-0.15$ to -0.02$)$ & $-0.06(-0.12$ to 0.00$)$ & $-0.03(-0.14$ to 0.08$)$ \\
\hline $\begin{array}{l}\text { No car access - car } \\
\text { access }\end{array}$ & $-0.07(-0.16$ to 0.00$)$ & $-0.05(-0.13$ to 0.03$)$ & $0.00(-0.08$ to 0.09$)$ \\
\hline $\begin{array}{l}\text { Shared bedroom - } \\
\text { bedroom of own }\end{array}$ & $-0.08(-0.14$ to -0.01$)$ & $-0.06(-0.12$ to 0.00$)$ & $-0.04(-0.10$ to 0.02$)$ \\
\hline
\end{tabular}

$\mathrm{SD}=$ standard deviation ( 1 standard deviation $\mathrm{FEF}_{25-75}=0.70 \mathrm{I}$ )

*Adjusted for nurse, age, and height squared.

†Adjusted for nurse, age, height squared, smoking, body mass index, physical activity, adult social class, and respiratory treatment.

$\ddagger$ Adjusted for nurse, age, height squared, smoking, body mass index, physical activity, adult social class, respiratory treatment, and each of the other childhood indicators of SEP (first column).

lung volume, peripheral airways obstruction, or both. FVC largely reflects lung volume, $\mathrm{FEV}_{1}$ is influenced by both airways flow obstruction and lung volume, whereas $\mathrm{FEF}_{25-75}$ is a more sensitive indicator of peripheral airways obstruction. ${ }^{20}$ Our main results therefore suggest that childhood poverty is associated both with reduced lung volume and peripheral airways obstruction in later life.

Lung function is associated with survival and cardiovascular disease in older age in both smokers and nonsmokers. ${ }^{1-3}$ The explanation for this association is unclear

Table 5 Cumulative effect of childhood socioeconomic position on adult forced expiratory volume in 1 second $\left(\mathrm{FEV}_{1}\right)$

\begin{tabular}{llll}
\hline $\begin{array}{l}\text { No of adverse childhood } \\
\text { socioeconomic indicators* }\end{array}$ & $\mathrm{N}$ & \multicolumn{2}{l}{ Difference $(95 \% \mathrm{Cl})$ in FEV $\mathbf{l}$ (SD) } \\
\cline { 3 - 4 } & 245 & Model 1+ & Moderence $2 \ddagger$ \\
\hline None & 470 & $-0.09(-0.23$ to 0.04$)$ & Reference \\
1 & 815 & $-0.23(-0.36$ to -0.11$)$ & $-0.06(-0.19$ to 0.07$)$ \\
2 & 806 & $-0.30(-0.42$ to -0.17$)$ & $-0.21(-0.27$ to -0.03$)$ \\
3 & 501 & $-0.36(-0.50$ to -0.23$)$ & $-0.27(-0.40$ to -0.09$)$ \\
4 & 804 & $-0.36(-0.48$ to -0.23$)$ & $-0.25(-0.36$ to -0.12$)$ \\
5 & & p trend $<0.001$ & p trend $<0.001$ \\
\hline
\end{tabular}

$\mathrm{SD}=$ standard deviation (1 standard deviation $\left.\mathrm{FEV}_{1}=0.52 \mathrm{l}\right)$.

*Number of adverse socioeconomic indicators = an individual's sum of belonging to manual social class in childhood, living in a house with no bathroom as a child, living in a house with no hot water as a child, no family access to a car as a child, and sharing a bedroom as a child. †Adjusted for nurse, age, and height squared.

$\ddagger$ Adjusted for nurse, age, height squared, smoking, body mass index, physical activity, adult social class, and respiratory treatment. 


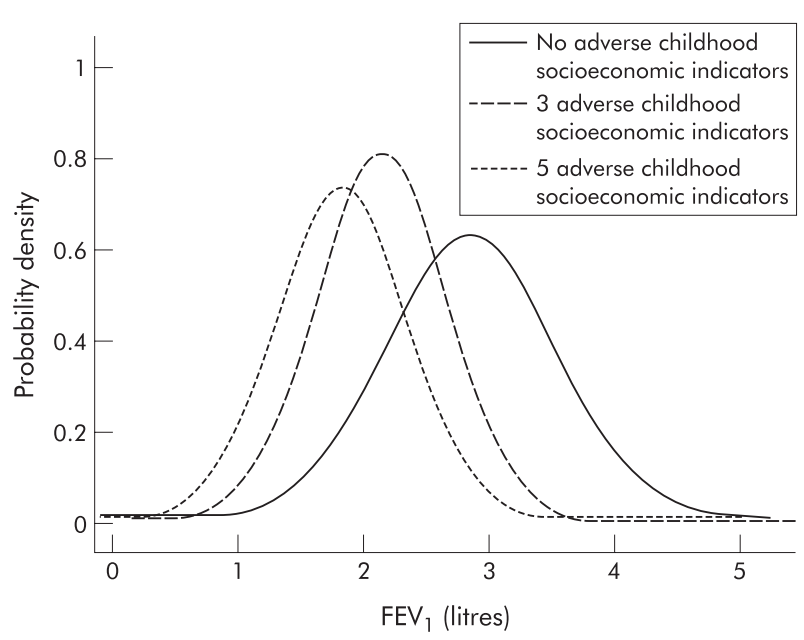

Figure 1 Distributions of forced expiratory volume in 1 second $\left(\mathrm{FEV}_{1}\right)$ for women with no adverse childhood socioeconomic indicators, three adverse childhood socioeconomic indicators, and all five adverse socioeconomic indicators.

but it does not appear to be explained by confounding due to smoking, adult social class, or other potential confounders. Although $\mathrm{FEV}_{1}$ tends to be lower in sick people, illness bias does not appear to explain the association between $\mathrm{FEV}_{1}$ and cardiovascular disease since the association remains even when individuals who have died within 5,10 , or 15 years of the baseline examination have been removed from the analyses in large prospective studies. ${ }^{2}{ }^{3}$ One possible explanation for the association is that early life factors that affect lung growth and development-and thence maximal attained lung function in adulthood-also influence cardiovascular disease and explain the association between $\mathrm{FEV}_{1}$ and coronary heart disease. Several studies have shown adverse childhood socioeconomic circumstances to be associated with increased cardiovascular disease, independent of adult socioeconomic position..$^{21-23}$ Our findings support the hypothesis that the association between lung function and cardiovascular disease may at least be partly explained by lung function in adulthood being an indicator of childhood poverty. Alternatively, poor lung function may be an important mediator in the association between childhood poverty and increased risk of coronary heart disease. Future studies need to concentrate on identifying the pathways through which childhood poverty results in poorer lung function and increased cardiovascular disease in older age.

Our findings add to the growing body of evidence that the adverse impact of childhood poverty on health persists into late adulthood. Although women in this study were born between 1920 and 1940 when socioeconomic conditions in general were poor, lung function in contemporary children is associated with poor socioeconomic circumstances, ${ }^{24}$ suggesting that childhood poverty in today's society can still influence lung function. In contemporary Britain recent estimates suggest that one in three children live in poverty, defined as living in a household with an income of less than half the mean income for the whole of Britain, ${ }^{25}$ and our results emphasise the importance of government policy aimed at reducing childhood poverty and its associated health consequences across the life course. ${ }^{26}$

\section{ACKNOWLEDGEMENTS}

The authors thank all the general practitioners and their staff who have supported data collection and the women who have participated in the study.

\section{Authors' affiliations}

D A Lawlor, S Ebrahim, G Davey Smith, Department of Social Medicine, University of Bristol, Bristol, UK

The British Women's Heart and Health Study is funded by the Department of Health. Dr Lawlor is funded by a Medical Research Council/Department of Health (UK) training fellowship when this work was undertaken and is now funded by a Department of Health career scientist award. The views expressed in this publication are those of the authors and not necessarily those of the Department of Health or MRC.

Conflict of interests: none.

\section{REFERENCES}

1 Strachan DP. Ventilatory function, height, and mortality among lifelong nonsmokers. J Epidemiol Community Health 1992;46:66-70.

2 Hole DJ, Watt GC, Davey Smith G, et al. Impaired lung function and mortality risk in men and women: findings from the Renfrew and Paisley prospective population study. BMJ 1996;313:711-5.

3 Schunemann HJ, Dorn J, Grant BJ, et al. Pulmonary function is a long-term predictor of mortality in the general population: 29-year follow-up of the Buffalo Health Study. Chest 2000;1 18:656-64.

4 Strachan DP. Respiratory and allergic diseases. In: Kuh D, ed. A life course approach to chronic disease epidemiology. Oxford: Oxford University Press 1997:101-20.

5 Dezateux C, Stocks J. Lung development and early origins of childhood respiratory illness. Br Med Bull 1997; 53:40-57.

6 Sherrill DL, Lebowitz MD, Knudson RJ, et al. Smoking and symptom effects on the curves of lung function growth and decline. Am Rev Respir Dis 1991;144:17-22.

7 Barker DJP, Godfrey KM, Fall C, et al. Relation of birth weight and childhood respiratory infection to adult lung function and death from chronic obstructive airways disease. BMJ 1991;303:671-5.

8 Rona RJ, Gulliford MC, Chinn S. Effects of prematurity and intrauterine growth on respiratory health and lung function in childhood. BMJ 1993;306:817-20.

9 Stein CE, Kumaran K, Fall CH, et al. Relation of fetal growth to adult lung function in south India. Thorax 1997;52:895-9.

10 Wist M, Popescu M, Trepka MJ, et al. Pulmonary function in children with initial low birth weight. Pediatr Allergy Immunol 1998;9:80-90.

11 Cook DG, Strachan DP, Carey IM. Health effects of passive smoking. 9. Parental smoking and spirometric indices in children. Thorax 1998;53:884-93.

12 Strachan DP, Griffiths JM, Anderson HR, et al. Association of intrauterine and postnatal growth with ventilatory function in early adult life. Thorax 1994:49: 1052P.

13 Shaheen SO, Sterne JAC, Montgomery SM, et al. Birth weight, body mass index and asthma in young adults. Thorax 1999;54:396-402.

14 Upton MN, Watt GC, Davey SG, et al. Permanent effects of maternal smoking on offsprings' lung function. Lancet 1998;352:453.

15 Blane D, Hart CL, Smith GD, et al. Association of cardiovascular disease risk factors with socioeconomic position during childhood and during adulthood. BMJ 1996;313:1434-8

16 Heslop P, Davey Smith G, Macleod J, et al. The socioeconomic position of women, risk factors and mortality. Soc Sci Med 2001;53:477-85.

17 Lawlor DA, Bedford C, Taylor M, et al. Geographic variation in cardiovascular disease, risk factors and their control in older women: British Women's Heart and Health Study. J Epidemiol Community Health 2003:57:134-40.

18 Cole TJ. Linear and proportional regression models in the prediction of ventilatory function. J R Stat Soc Ser A 1975;138:297-324.

19 Erens B, Primatesta P. Health survey for England: cardiovascular disease. London: The Stationery Office, 1999.

20 Higgins MW, Keller JB. Seven measures of ventilatory lung function. Population values and a comparison of their ability to discriminate between persons with and without chronic respiratory symptoms and disease, Tecumseh, Michigan. Am Rev Respir Dis 1973;108:258-72.

21 Lawlor DA, Davey Smith G, Ebrahim S. The association of childhood socioeconomic position with coronary heart disease risk in post-menopausal women: findings from the British Women's Heart and Health Study. Am J Public Health 2004 (in press).

22 Claussen B, Davey Smith G, Thelle D. Impact of childhood and adulthood socioeconomic position on cause specific mortality: the Oslo Mortality Study 1. J Epidemiol Community Health 2003;57:40-5.

23 Wamala SP, Lynch J, Kaplan GA. Women's exposure to early and later life socioeconomic disadvantage and coronary heart disease risk: the Stockholm Female Coronary Risk Study. Int J Epidemiol 2001;30:275-84.

24 Demissie K, Ernst P, Hanley JA, et al. Socioeconomic status and lung function among primary school children in Canada. Am J Respir Crit Care Med 1996;153:719-23.

25 Gregg P, Harkness S, Machin S. Poor kids: trends in child poverty in Britain, 1968-96. Fiscal Studies 1999;20:163-87.

26 Department of Health. Tackling health inequalities, improving public health, Speech by the Secretary of State for Health to the Faculty of Public Health Medicine, 20 November 2002 (available at http://www.fphm.org.uk, accessed January 2003). 